\title{
On the Necessity of Referral to the Category "Randomity" In the Process of Moral Assessment of Individual's Acts
}

\author{
Makuhin Petr Gennadyevich, Ph.D. \\ Associate Professor of the Department of History, Philosophy and Social \\ Communications, Omsk State Technical University, Omsk, Russia
}

\begin{abstract}
In the article, firstly, through the analysis of the history of ethical teachings, the basic requirements for the procedure of moral assessment, for its subject (the legitimacy of this assessment) and the object (taking into account the consequences of the act, their motives, as well as the ratio of the goal and the means used to achieve it) are identified. Consideration of a particular deed taking into account all these aspects, it would seem, allows us to make its moral assessment objective, impartial, fair. However, secondly (and most importantly!), we substantiate the thesis that if this consideration is not supplemented with the category of randomity (moreover, interpreted as a clinamen), then the resulting assessment will itself be morally problematic, giving rise to "moral complacency" and depriving us the opportunity to help a morally stumbled person.
\end{abstract}

Key words: moral assessment, randomity (as a dialectical complement to necessity and as a clinamen), history of ethics (Bible, J. Bentham, J. S. Mill, I. Kant, F. M. Dostoevsky, L. N. Tolstoy, N. A. Nekrasov, M. Gandhi, A. Schweitzer).

Introduction. We are aware that the position indicated in the title may cause surprise, and moreover, seem provocative - they say, such an approach "dilutes" the severity of moral assessments, giving a person who violated moral norms the opportunity to justify himself in this way: "this situation happened by accident" (or even: "I did it by accident"). Nevertheless, we will try to justify the need to take into account the factor of "randomity" in this area; but first it is necessary to consider those requirements for the procedure of moral assessment, which by the third decade of the XXI century firmly entered the "cultural baggage of humanity." The first paragraph of the article will be devoted to this; the second is a philosophical reflection on the category of "randomity". As a result, it will be shown that the latter, on the one hand, can be interpreted as a dialectical complement to "necessity", and on the other, as pure spontaneity, which was recorded in antiquity by the concept of "clinamen". It is to this "spontaneity", "unpredictability", as we will try to substantiate, that it is necessary to appeal in the process of evaluating the moral component of someone's actions.

1. Basic requirements for the object and subject of moral assessment in the history of ethics. The designated assessment, first, must take into account the consequences of the act. On this in the history of ethics, a special emphasis was made by representatives of the school of utilitarianism - the English philosophers and humanitarians J. Bentham (1748- 
1832) and J. S. Mill (1806-1873); according to the first of them, "the principle of the greatest (possible) happiness" "approves or disapproves of any action, depending on whether it has ... the desire to increase or decrease happiness" [1, p. 10] as many persons as possible. Or - the desire "to prevent harm, suffering, evil or misfortune" [1, p. 10] specified persons. To put it more simply, utilitarians formulated the "principle of utility", according to which an act that leads to an increase in the pleasure of the maximum number of people should be recognized as correct from a moral point of view. The second of the named representatives of utilitarianism makes a special emphasis on this: "whether nobility will bring more happiness to its owner is still a question, but there is no doubt that it will make other people happier, and the world as a whole will benefit greatly" [2, p. 59].

On the one hand, one cannot but recognize an element of truth in this approach: utilitarianism brought ethics beyond the moral emotions of individuals, obliging a person not only to experience, for example, compassion, but also to act on the basis of this feeling. Moreover, to act in the interests not only of people he knows, but also of society as a whole. On the other hand, it is impossible in all cases to calculate the consequences of a particular act, because many of them do not come immediately. Therefore, an act that yesterday was regarded as moral today becomes immoral if its not obvious consequences "appear"; moreover, it is impossible to imagine how it will be evaluated tomorrow.

First, it is necessary to take into account the motives of the act, which was put at the forefront by one of the greatest German and broader world thinkers - I. Kant (1724-1804). He differentiated the actions of a person into those that are carried out "by inclination" (for example, to give alms to a beggar because the latter aroused compassion), "under duress" (to give to a beggar who, for example, threatens with a knife), and, accordingly, "on duty ". Before giving an example of the latter, let us say that only the latter are regarded by the German philosopher as truly moral; their essence lies in the fact that a person, suppressing his own inclinations, acts as a moral duty requires of him. This requires, firstly, the awareness of the latter, that is, ethical knowledge; secondly, volitional efforts, that is, self-compulsion. In this connection, the German philosopher categorically asserts: there is nothing in this world, "that could be considered good without restriction, except for goodwill alone" [3, p. 161]. On this basis, let us finally formulate an example of this, again turning to the hypothetical beggar. Above, we modeled a situation when he aroused our sympathy, and here we will add the 
reason for this: suppose we saw in him an "old worker" who worked all his life, but a small pension does not allow him to survive. And now, in order to give an example of the only moral motive, from the point of view of I. Kant, let us change the situation: imagine an old criminal who has done nothing useful for society in his entire life, on the contrary, robbed honest people, and in old age cynically uses human kindness without hiding contempt for them. Accordingly, neither humanism nor justice (understood in the spirit of the tradition dating back to Aristotle as "equality of action and retribution", which was described in the last article in the same issue of the magazine) will not "push" us to give alms to this beggar, unsympathetic to us. However, despite the "silent emotions", we can still help him if we force ourselves to do this with the help of the will, guided by the Kantian "categorical imperative", as formulated in the "Foundations of the Metaphysics of Morals": "do so that you always relate to humanity both in his own person and in the person of everyone else as well as a goal, and would never treat it only as a means" [3, p. 205]. In his other most important ethical work, "Critique of Practical Reason" (we note that by such reason the Königsberg thinker meant just will as the basis for newness) I. Kant wrote: "will, the law for which can only be a pure legislative form of maxim there is free will "[4, p. 406]. Let us clarify that the representative of German classical philosophy meant "the principle according to which the subject acts" [3, p. 195], and it is the subject himself who instilled this thanks to reason and establishes, in thanks to the will - follows it. Therefore, according to the German classical philosopher, an act is moral - paradoxically - only if it is carried out against the wishes, emotions, inclinations of a person! To clarify this, let us say that, following T. Hobbes, I. Kant considers man to be an evil creature by nature.

Thirdly, the ratio of ends and means, which especially worried the Russian philosophizing writers: F. M. Dostoevsky, L. N. Tolstoy, N. A. Nekrasov, etc. The words of the first of them, "put into the mouth" of one of the characters of "The Brothers Karamazov", received worldwide fame: "I completely reject the highest harmony. It is not worth the tears of at least one tortured child" [5]. The second of these writers is classified - along with other prominent world theorists of non-violence, the Indian M. Gandhi and the German A. Schweitzer - as representatives of the so-called "abstract humanism". This is one of the "poles" in solving the problem of the relationship between "ends and means"; the opposite "pole" is "Jesuitism", also called "Machiavellianism" (in honor of the Order of the Jesuits and N. Machiavelli, 
masters and apologists of manipulation). The names of the positions "speak for themselves": the first of them insists that "the actual value of funds entirely determines the value of the results achieved" [6, p. 319]. The second, on the contrary, believes that "the end certainly justifies the means" [6, p. 319].

To these three aspects concerning the object of moral assessment, we add one more, concerning the subject of the latter. The point is that such an assessment should be legitimate, which is clearly expressed in the following words of the Bible (from Luke 6: 1): "Why are you looking at the mote in your brother's eye, but you don't feel the beam in your eye?" [7]. Turning to secular ethics, let us cite the thought of the Soviet expert on the problem of justice, Z. A. Berbeshkina: this virtue includes three aspects - the measure of reward, the measure of demand and the legitimacy of the assessment. The first of them was considered on the example of the ideas of Aristotle in our other article in the same journal. The second assumes that we must make the same moral requirements for all people, be they our friends or enemies. And, finally, the most important moment for us here is the third, which presupposes high moral requirements for oneself [8, p. 113].

2. "Accidental" in the mirror of philosophical reflection. One cannot but agree with O. A. Samoilova, a modern Russian researcher of the problem of chance, that the latter "is one of the basic, primary for ontology and the theory of knowledge, and it has not lost its relevance over many centuries of scientific research" [9, p. 3]. We, we repeat, want to show the significance of this category for ethics. As a starting point, we use the following definition of the concept of "randomity": a philosophical category that fixes that kind of limiting relationships, which is characterized by "the absence of direct regular relationships in the behavior and functioning of objects and systems" [10, p. 569]. We are talking about a phenomenon introduced into any area of "outside" reality, and, therefore, not predictable on the basis of knowledge about this area [11, p. 53]. In other words, there is a "case": "the onset of an unforeseen, unforeseen event, and especially its unforeseen coincidence with other events" [12, p. 418]. Accordingly, "accidental" in the philosophical literature is called the events generated by the "chain of unknown causes and effects." (Here we must not forget that the results of your natural, goal-setting activity affect another subject as random factors, just as the same results of his activity become random interventions for you). Considering this with the example of dice, we find the following remark: if a number, for example, by chance 
we got "5", it means the following. The reasons for the emergence of exactly the "five" "are too many and too great their independence from our will, so that, throwing the dice, we hoped to foresee or choose the result at will" [13, p. 537].

Having considered the basic definitions of the concept of "randomity", let us point out two main approaches to this phenomenon in the history of philosophy. The first is the interpretation of chance as a "dialectical complement to necessity", which was most consistently substantiated by G. W. F. Hegel. In the "Science of Logic", he paradoxically asserts: "a real need for oneself is in fact also an accident" [14, p. 197]. Not being able to explain this thesis here, we will confine ourselves to the following words of F. Engels (who, together with K. Marx, undertook the grandiose work of a materialist interpretation of Hegel's idealist dialectics). The aspirations of many citizens of any society will certainly "overlap", and in all societies, "therefore, necessity dominates, the addition and form of manifestation of which is chance" [15, p. 175].

But for our article, the second version of the interpretation of "randomity" is more important namely, as a clinamen. Note that the last term in the philosophy of Epicurus (342/341-270 BC) and Titus Lucretius Carus (about 99-55 BC), meant "a barely noticeable deviation of atoms, which pushes them in an indefinite place and time" [16, p. 254]. In the book "On the nature of things" the second of the named philosophers wrote about this process as follows: "this circumstance the slight declination of the primordial-atoms causes, though it takes place neither in any determinate part of space, nor at any determinate time" [17, p. 67]. But to this seemingly not the most important point, these ancient atomists attached fundamental importance, which was well shown by the famous Italian historians of philosophy G. Reale and D. Antiseri. According to the latter, since such a "deviation" can occur "at any moment of time and at any point in space", i.e., completely unpredictable, Epicurus can be described as a thinker "who rebuilt the world on occasion" [18, p. 184]. With this approach, so to speak, $a$ random event looks even more random than in the first case, when the randomness of this event was assessed as a dialectical complement to the regularity behind what happened.

Here are examples of each of these two aspects of randomness (of course, given that in real life it is not so easy to separate them). Imagine that I regularly leave home for work on time "end-to-end", that is, without having any "time reserve". And if just today on the way to work an accident happens, then my precisely today's delay for work will be accidental (because 
factors uncontrollable by me, for example, the bus broke down), but through this accident a pattern will appear (consisting in that if you don't leave the house in advance, there is a risk of being late: today, tomorrow, or in a week). And a completely different situation will take place in the case when I am afraid of being late for work, I always go out with a "reserve of time", for example, half an hour, but suddenly an accident occurs on the way that will make me be late, in spite of everything the "precautions" taken. In the second case, we can evaluate randomness as a clinamen.

Conclusions. By "connecting together" all the designated "semantic blocks", let us simulate the following situation: taking into account both the motives and consequences, and the ratio of ends and means, we evaluate someone's act as immoral. Further, referring to our previous article in the same issue of the journal, let us assume two situations. The first of them deals with the citizen as a whole of a just society, and we will adhere to the position developed by Socrates, Plato and Aristotle. And then we have a basis for moral indignation: this person had the opportunity to behave morally, but neglected this opportunity! In the second hypothetical situation, we are talking about a member of an unjust, immoral society, but since we adhere to the position of the Stoics, we believe that this person had the opportunity - and moreover, he was obliged! - to act contrary to common stereotypes of behavior. (Of course, other options are possible, but they are less "sharp": for example, if we are dealing with a "morally stumbling" citizen of an immoral society, but at the same time we adhere to the point of view of the Athenian philosophers, then we have no grounds for an unambiguous, consistent, uncompromising moral conviction). Moreover, as an initial condition, we postulate that in both cases we are not those who were condemned in the Bible as "hypocrites", "pharisees". In other words, in the terminology of Z.A. Berbeshkina, our moral assessment of a hypothetical violator of moral norms is fair in all three aspects, incl. it is "legitimate" because we ourselves do not violate the designated norms.

However, as we pointed out at the beginning of the article, such a condemnation is itself morally problematic, and now we will explain why. Because in any moral perfection (in our hypothetical case: characteristic of the subject of moral assessment, that is, ourselves), and in any moral fall (respectively: characteristic of the object of such an assessment, that is, for example, a criminal), there is an element of chance. That is - as we examined in the last paragraph - we are talking about events, factors, motives, "introduced" into the life of a 
particular person "from the outside" and, therefore, not predictable either by this person himself or by anyone else. In other words, we are talking about the occurrence of an "accident", that is, an "unexpected, unforeseen event", or about "unforeseen coincidence with other events." Moreover, we are interested in randomness here not so much as a dialectical complement to necessity (for example, if a person regularly abuses alcohol, then a seemingly random outbreak of "drunken rage" that made him beat someone is, in fact, natural), but also as clinamen (let's change our example: we are talking about rage caused by an unpredictable, unpredictable situation, falling into which even an absolutely sober person can inflict beatings on someone, as in the previous example).

Of course, the role of randomness understood as such cannot be exaggerated and, moreover, absolutized, as was the case within the mythological worldview, where the omnipotence of Destiny (Fate, Fatum) "erased" the distinction between "saints and sinners". The latter could only be pitied - as, for example, the patricide and incestuous Oedipus, who from the moment of birth was doomed to these vile crimes. However, the opposite extreme the complete disregard for the factor of chance in the moral assessment of both someone and oneself - also distorts this assessment, generating "moral complacency" and not allowing sympathy for an immoral person as, to a certain extent, a victim of random circumstances. And without this sympathy, empathy, interest, it is impossible to help him overcome the indicated immorality, while such help should be the goal of moral assessment!

\section{References}

1. Bentham J. Introduction to the foundations of morality and legislation. M.: ROSSPEN, 1998. p. 416

2. Mill J. S. Utilitarianism. Rostov-on-Don: Donskoy Publishing House, 2013, p. 240

3. Kant I. Foundations of the metaphysics of morals // I. Kant Works: In 8 volumes. v. 4. M.: Choro, 1994. P. 153-246.

4. Kant I. Critique of practical reason // I. Kant Works: In 8 volumes. v. 4. M.: Choro, 1994. P. 373-565.

5. Dostoevsky F. M. Brothers Karamazov [Electronic resource] Access mode: https://ilibrary.ru/text/1199/p.36/index.html

6. Apresyan R. G. Purpose and means // New philosophical encyclopedia: In 4 volumes. v. 4. - M.: Mysl, 2010. P. 319-320.

7. Online Bible [Electronic resource] Access mode: https://bibleonline.ru/bible/rst66/luk$\underline{6.42 /}$ 
8. Berbeshkina Z. A. Justice as a socio-philosophical category. 1983. p. 208

9. Samoilova O. A. Accident in nature: ontological analysis: dis. ... candidate of philosophical sciences: 09.00.01 [Saratov National Research State University named after N. G. Chernyshevsky], 2019. p. 131

10. Sachkov Yu. V. Randomness // New philosophical encyclopedia: In 4 volumes. V. 3. 2nd ed. - M.: Mysl, 2010. P. 569-570.

11. Levin G. D. Necessity and accident // New philosophical encyclopedia: In 4 volumes. v. 3. 2nd ed. - M .: Mysl, 2010. P. 53-54.

12. Case // Philosophical Encyclopedic Dictionary / ed.- Gubsky E. F. [and others]. M.: INFRA-M, 1999. P. 418.

13. A. Comte-Sponville Impromtus // A. Comte-Sponville Philosophical Dictionary. M .: Palimpsest, Eterna Publishing House. 2012. P. 537.

14. Hegel G. W. F. Science of Logic: In 3 volumes. Vol. 2. M .: "Mysl", 1971. p. 248

15. Engels F. Letter to W. Borgius, January 25, 1894 // K. Marx, F. Engels Works. Second Edition v. 39. - M .: Publishing house of political literature, 1966. P. 174-177.

16. A. Comte-Sponville Impromtus // A. Comte-Sponville Philosophical Dictionary. M.: Eterna, 2012. P. 254.

17. Titus Lucretius Carus On the Nature of Things. M.: Khudozhestvennaya literatura, 1983. p. 383

18. Reale G., Antiseri D. Western philosophy from the beginning to the present days. I. Antiquity. SPb .: TOO TK "Petropolis", 1997. p. 336 